\title{
Effect of Pre-Aging, Over-Aging and Re-Aging on Exfoliation Corrosion and Electrochemical Corrosion Behavior of Al-Zn-Mg-Cu Alloys
}

\author{
Xingzhi Liao1,2, Xiaohua Kong1,2, Pengxuan Dong1,2, Kanghua Chen ${ }^{1,2,3}$ \\ ${ }^{1}$ Science and Technology on High Strength Structural Materials Laboratory, Central South University, Changsha, China \\ ${ }^{2}$ Collaborative Innovation Center of Advance Nonferrous Structural Materials and Manufacturing, Central South University, \\ Changsha, China \\ ${ }^{3}$ Light Alloy Research Institute, Central South University, Changsha, China \\ Email:357793589@qq.com
}

How to cite this paper: Liao, X.Z., Kong, X.H., Dong, P.X. and Chen, K.H. (2020) Effect of Pre-Aging, Over-Aging and Re-Aging on Exfoliation Corrosion and Electrochemical Corrosion Behavior of $\mathrm{Al}-\mathrm{Zn}-\mathrm{Mg}-\mathrm{Cu}$ Alloys. Journal of Materials Science and Chemical Engineering, 8, 81-88. https://doi.org/10.4236/msce.2020.82008

Received: January 19, 2020

Accepted: February 23, 2020

Published: February 26, 2020

Copyright $\odot 2020$ by author(s) and Scientific Research Publishing Inc. This work is licensed under the Creative Commons Attribution International License (CC BY 4.0).

http://creativecommons.org/licenses/by/4.0/

\begin{abstract}
By means of TEM, hardness, conductivity, tensile strength test, fracture toughness test, polarization curve and EIS, the $\mathrm{Al}-\mathrm{Zn}-\mathrm{Mg}-\mathrm{Cu}$ alloys treated by a new multi-stage aging system, i.e. pre-aging, over-aging and re-aging $\left(120^{\circ} \mathrm{C} / 24 \mathrm{~h}+160^{\circ} \mathrm{C} / 8 \mathrm{~h}+120^{\circ} \mathrm{C} / 24 \mathrm{~h}\right)$, were characterized. It is found that compared with the Al- $\mathrm{Zn}-\mathrm{Mg}-\mathrm{Cu}$ alloys treated by $\mathrm{T} 76\left(120^{\circ} \mathrm{C} / 24 \mathrm{~h}+\right.$ $160^{\circ} \mathrm{C} / 8 \mathrm{~h}$ ), the new multi-stage aging treatment can improve the tensile strength, fracture toughness, hardness and conductivity of the alloys at the same time. This is mainly due to the pre-aging, over-aging and re-aging process of super high strength aluminum alloys. Compared with the two-stage over aging process, the formation of multi-stage multi-phase precipitation structure can improve the strength, toughness and corrosion resistance of the alloys at the same time. The polarization curve is consistent with the conclusion. Therefore, we conducted this study to test how the comprehensive properties of the alloy can be improved.
\end{abstract}

\section{Keywords}

Al-Zn-Mg-Cu-Zr Alloys, Pre-Aging, Over-Aging and Re-Aging, Exfoliation Corrosion, Electrochemical Corrosion

\section{Introduction}

Super high strength, high toughness and corrosion-resistant aluminum alloy has the advantages of low density, high strength and good hot working performance [1] [2] [3] [4]. It has been widely used in aerospace industry, vehicles, buildings, 
bridges, engineering equipment and large pressure vessels [5]-[12] which is the main structural material in aerospace industry. At present, the aluminum alloy on the aircraft of all countries in the world has accounted for $70 \%-80 \%$ of the weight of structural materials, most of which are ultra-high strength aluminum alloy [13]. In recent years, scientists have developed a variety of ultra-high strength aluminum alloys with better performance by optimizing alloy composition design, improving alloy forming and heat treatment process. The sequence of precipitation structure of 7000 system aluminum alloy is as follows: supersaturated solid solution $\rightarrow$ continuous GP zone $\rightarrow$ semi-continuous unstable $\eta$ phase $\rightarrow$ discontinuous stable $\eta$ phase [14]-[20]. The alloy obtained by peak aging (T6: $120^{\circ} \mathrm{C} / 24 \mathrm{~h}$ ) has the highest strength, but it is prone to local corrosion. Therefore, in this paper, we consider to optimize the heat treatment conditions of the alloy to obtain the alloy which can improve the strength and corrosion resistance of the alloy at the same time.

\section{Experimental}

The alloy material used in this paper is 7055 with thickness of $20 \mathrm{~mm}$. Its composition is $\mathrm{Zn} 8.54 \%, \mathrm{Mg} 2.41 \%, \mathrm{Cu} 1.5 \%$, and the rest is aluminum. The sample is first dissolved at $480^{\circ} \mathrm{C} 30 \mathrm{~min}$ and then quenched, and then treated by different aging methods, as shown in Figure 1. A long time aging treatment will make the $\eta$ ' phase of the sample change into $\eta$ phase, which is difficult to be dissolved in the process of re-aging. The intermediate aging time is $8 \mathrm{~h}$. The full text is based on the aging state of T76.

Tensile test is to test the smooth sample with css-44100 tester at room temperature. Transmission electron microscopy (TEM, jeol 2100-f) was used to observe the microstructure of large angle grain boundary in the precipitated phase of grain boundary.

EXCO is carried out according to the standard EXCO test method. The electrochemical behavior of the sample was carried out by polarization curve in $25^{\circ} \mathrm{C}$ and EXCO solution.

Electrochemical test is carried out in the electrochemical work station Chi 660C. The electrochemical system consists of three parts: saturated calomel electrode as reference electrode, platinum electrode as auxiliary electrode and alloy as working electrode. The polarization curve was carried out at the scanning
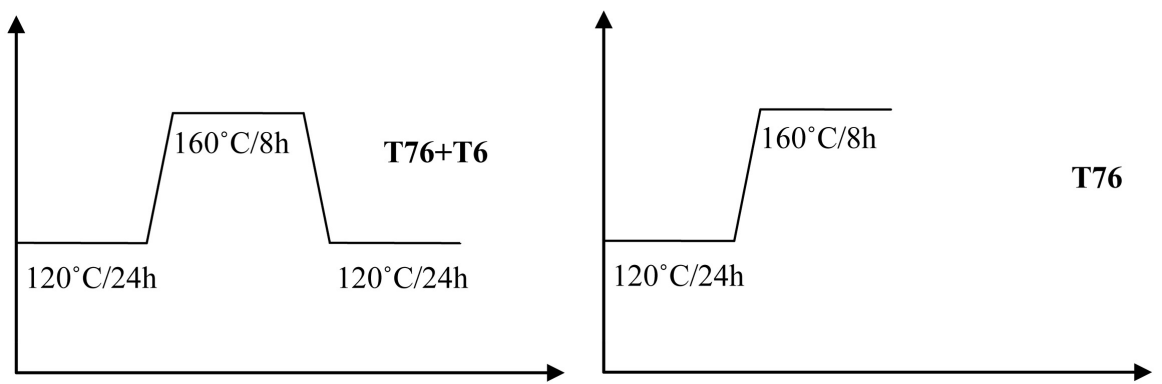

Figure 1. Different aging systems of 7055 alloy. 
speed of $10 \mathrm{mV} / \mathrm{s}$.

\section{Results and Discussions}

\subsection{Effect of Pre-Aging, Over-Aging and Re-Aging on Microstructure}

Figure 2 shows the microstructure of the aging state of T76 and the aging state of T76 + T6 of 7055 alloy. Compared with the T76 aging state, the size of the template particles in the T76 + T6 aging state is the same, but its particle size is smaller than that of T76. However, compared with T76 + T6 aging, the grain boundary precipitation of the samples obtained by T76 + T6 aging is coarser and rarer, and the fine GP region is precipitated in the grains, forming multi-stage multi-phase precipitation structure. Figure 3 is the TEM diagram of samples obtained by different aging systems. It can be seen from the figure that at $1 / 3\{220\}$ and $2 / 3\{220\}$ parallel to $\{111\}$ direction, the awn line is obviously stronger than that at two-stage aging, which shows that there is a new GP region formed after re-aging on the basis of slight two-stage over aging T76; the spot diffraction intensity of $\eta^{\prime}$ phase at $1 / 3\{220\}$ and $2 / 3\{220\}$ after new three-stage aging is also higher than that of T76, which shows that the volume fraction of $\eta^{\prime}$ phase is increasing Add. Therefore, the strength of the alloy increases, which can be reflected in the hardness.

\subsection{Effect of Pre-Aging, Over-Aging and Re-Aging on Hardness and Conductivity}

Table 1 shows the comparison of hardness and conductivity of different effective
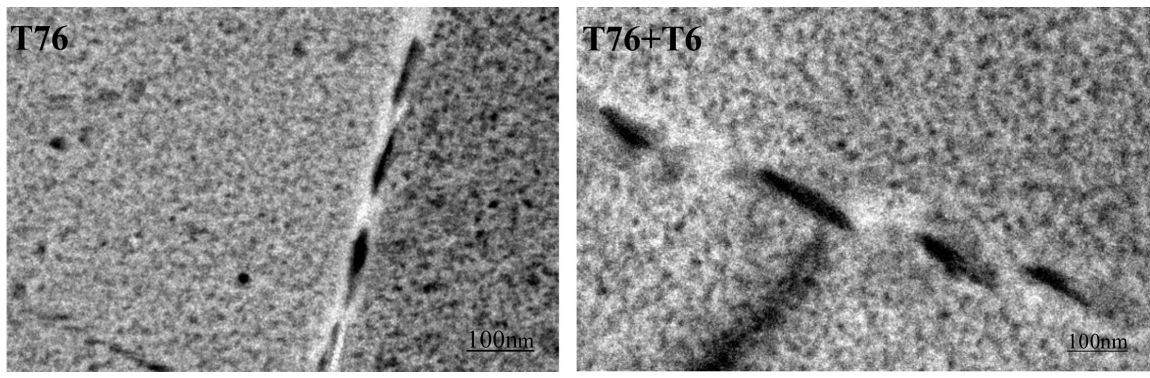

Figure 2. Changes of microstructure of samples obtained by different aging systems.

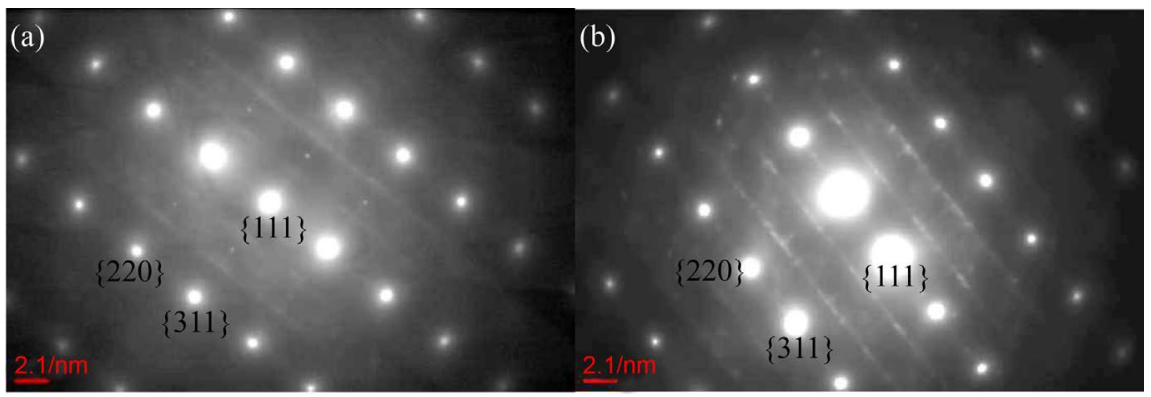

Figure 3. TEM of samples obtained by different aging systems. (a) T76 aging state; (b) T76 + T6 state. 
Table 1. Comparison of hardness and conductivity of alloy treated by different aging systems.

\begin{tabular}{ccccc}
\hline Component & \multicolumn{2}{c}{ Hardness } & \multicolumn{2}{c}{ Conductivity } \\
\hline \multirow{2}{*}{ Al-8.54Zn-2.41Mg-1.5Cu } & T76 & T76 + T6 & T76 & T76 + T6 \\
& 182 & 193 & 18.1 & 18.7 \\
\hline
\end{tabular}

states. The changes of hardness and conductivity correspond to the changes of microstructure. It can be seen from Table 1 that the hardness and conductivity of T76 + T6 samples are higher than that of T76 aging samples.

\subsection{Effect of Pre-Aging, Over-Aging and Re-Aging on Mechanical Properties}

Table 2 shows the comparison results of tensile strength, yield strength and fracture toughness of 7055 alloy after different effective treatment. It can be seen from the table that the tensile strength, yield strength and fracture toughness of the sample obtained by the pre-aging, over-aging and re-aging system are improved to a certain extent compared with the T76 aging state.

\subsection{Effect of Pre-Aging, Over-Aging and Re-Aging on Exfoliation Corrosion Behavior}

Figure 4 shows the exfoliation corrosion of 7055 alloy in different effective states. EXCO corrosion resistance can be used to classify EXCO corrosion rate: $\mathrm{ED}$ (severe exfoliation) $>\mathrm{EC}>\mathrm{EB}>\mathrm{EA} \sim \mathrm{p}$ (very small initial slight exfoliation). The left figure in Figure 4 shows the exfoliation corrosion diagram of T76 sample. It can be seen from the figure that a small amount of surface structure has been removed and only small particles have been observed. The peeling corrosion strength can be classified as EB. In contrast, only a few metal particles are separated from the corrosion surface of T76 + T6 samples, and the peeling corrosion strength can be classified as EA. Therefore, it can be concluded that the order of peel corrosion resistance is T76 + T6 better than T76.

\subsection{Effect of Pre-Aging, Over-Aging and Re-Aging on Intergranular Corrosion}

Figure 5 is the intergranular corrosion diagram of the alloy treated by two aging systems. It can be seen from the diagram that the corrosion depth of T76 + T6 state is shallower than that of T76 state, indicating that the new aging state T76+ T6 state can better improve the intergranular corrosion resistance of the sample compared with the two-stage aging state T76.

\subsection{Effect of Pre-Aging, Over-Aging and Re-Aging on Electrochemical Corrosion}

Figure 6 shows the electrochemical polarization curves of the samples treated by two aging systems. As shown in the figure, the electrode potential (about-0.72) 
Table 2. Comparison of tensile strength, yield strength and fracture toughness of alloy under different aging systems.

\begin{tabular}{ccccccc}
\hline Component & \multicolumn{2}{c}{ Tensile strength/MPa } & \multicolumn{2}{c}{ Yield strength/MPa } & \multicolumn{2}{c}{$\begin{array}{c}\text { Fracture } \\
\text { toughness/MPa }{ }^{\star} \mathrm{m}^{1 / 2}\end{array}$} \\
\hline Al-8.54Zn-2.41Mg-1.5Cu & $\mathrm{T} 76$ & $\mathrm{~T} 76+\mathrm{T} 6$ & $\mathrm{~T} 76$ & $\mathrm{~T} 76+\mathrm{T} 6$ & $\mathrm{~T} 76$ & $\mathrm{~T} 76+\mathrm{T} 6$ \\
& 697.5 & 713.4 & 684.1 & 696.8 & 37.2 & 38.4 \\
\hline
\end{tabular}
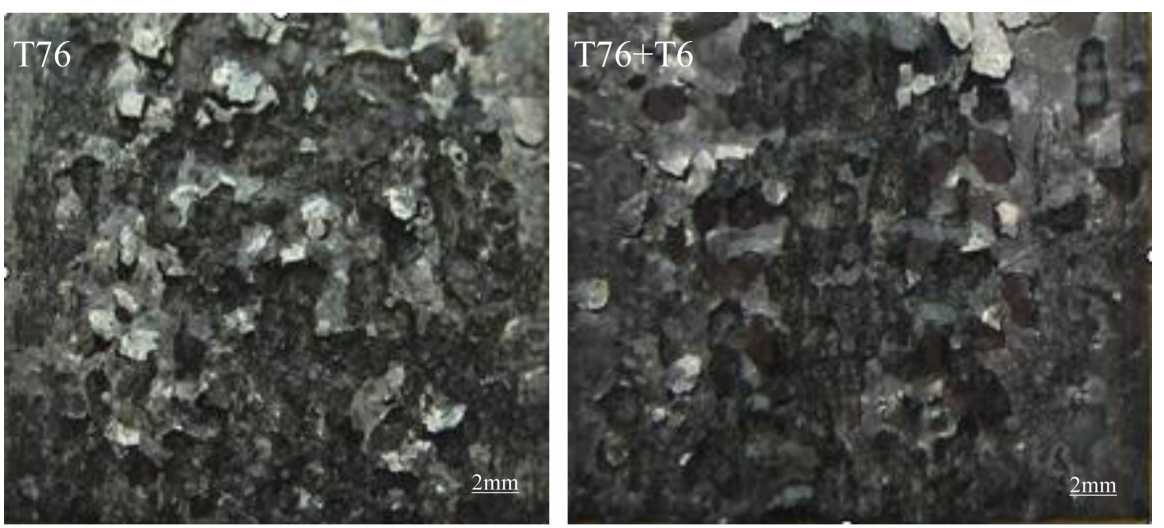

Figure 4. Comparison of exfoliation corrosion of alloy treated by two aging systems. On the left is the exfoliation corrosion diagram of T76 sample, on the right is the exfoliation corrosion diagram of T76 + re-aging sample.

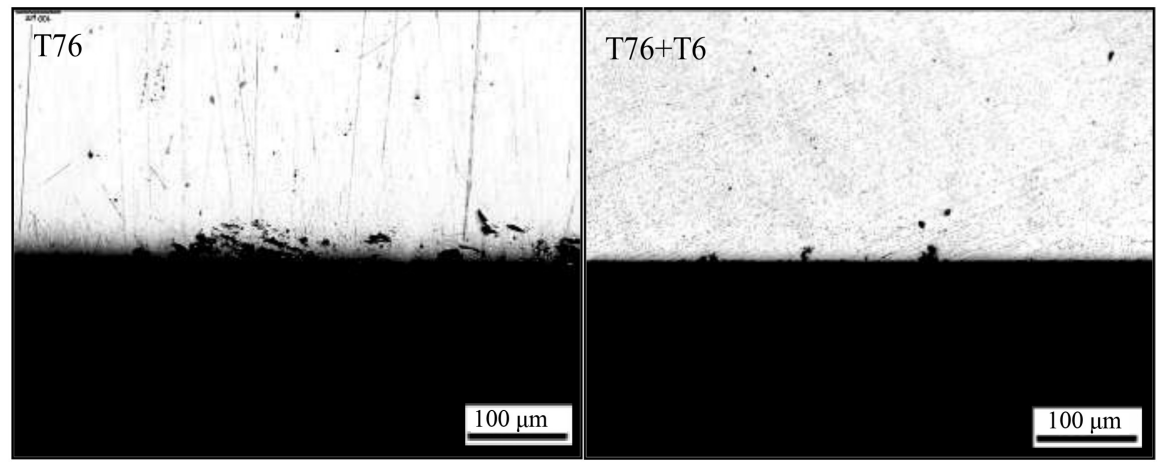

Figure 5. Comparison of intergranular corrosion of alloy treated by two aging systems.

of the T76 + re-aging sample after the polarization curve test is higher than that of the T76 sample after the polarization curve test (about-0.77).

It can be seen from the above data, compared with the double stage aging (T76), the re-aging stage in the pre-aging over-aging and re-aging system narrow or even disappear the non-precipitated phase band at the grain boundary when the alloy returns, which improves the strength of the grain boundary; at the same time, the crystal still maintains and obtains a more dispersive structure state and higher precipitation strengthening effect. The dispersed precipitated structure can strengthen the matrix, restrain coplanar slip and fracture.

Because exfoliation corrosion (EC) is developed from intergranular corrosion, EC is related to the precipitates at grain boundaries. If the coarser and rarer the precipitates are, the lower the efficiency of intergranular corrosion will be, so 


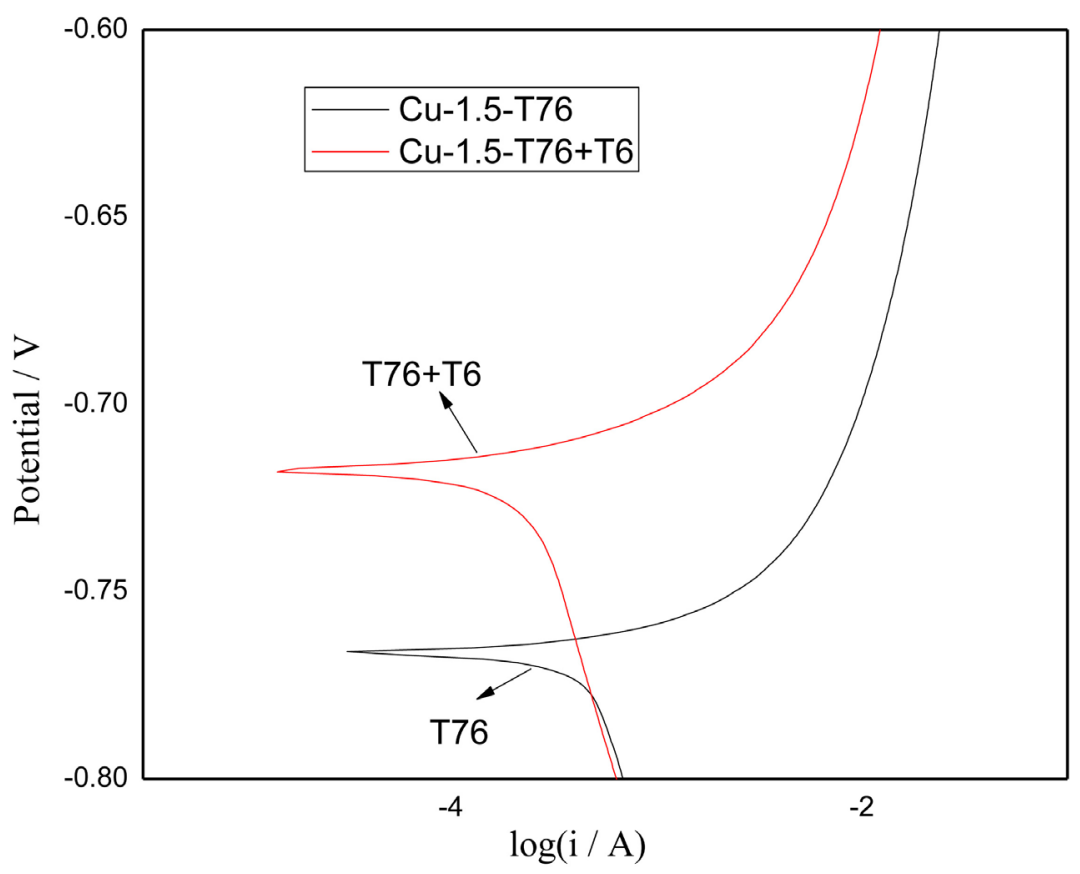

Figure 6. Comparison of polarization curves of alloy treated by two aging systems.

that the alloy has higher EC resistance. Moreover, the high content of $\mathrm{Cu}$ in the precipitated phase will increase the electrode potential of the precipitated phase, thus reducing the current between the precipitated phase and the alloy matrix, which can effectively improve the corrosion resistance of the alloy. Therefore, the precipitates on the grain boundary are larger, rarer and more $\mathrm{Cu}$ content can be obtained by pre-aging, over-aging and re-aging, which can significantly improve the exfoliation corrosion resistance of the samples compared with the two-stage aging T76.

It can be seen from the corrosion voltage of the alloy samples that the voltage of the pre-aging, over-aging and re-aging-samples is significantly higher than that of the double aging stage (T76) samples, which shows that the EC resistance of the pre-aging, over-aging and re-aging samples can be effectively improved compared with that of the double aging stage (T76) samples.

\section{Conclusions}

1) Compared with the two-stage aging (T76), the pre-aging, over-aging and re-aging process can improve the strength and corrosion resistance of the alloy at the same time.

2) The resistance to exfoliation is attributed to the coarseness and dispersion of the precipitates at the grain boundary. The coarser the alloy is, the better the resistance to exfoliation is, and vice versa. At the same time, the erosion resistance is also increased by the increase of $\mathrm{Cu}$ content in the precipitates.

3) The new aging state (T76 + T6) can improve the intergranular corrosion resistance of the alloy better than the double aging state (T76).

4) The results of electrochemical polarization curves are consistent with those 
of exfoliation and intergranular corrosion resistance.

\section{Acknowledgements}

This work was supported by the national key research and development program of China (No. 2016YFB0300801) major research equipment development projects of national natural science foundation of China (No. 51327902) Ph. D. student self-exploration (2014zzts024).

\section{Conflicts of Interest}

The authors declare no conflicts of interest regarding the publication of this paper.

\section{References}

[1] Pan, F.S. and Zhang, D.F. (2006) Aluminum Alloy and Its Application. Chemical Industry Press, Beijing, 59.

[2] Heinz, A., Haszler, A., Keidel, A., et al. (2000) Recent Development in Aluminium Alloys for Aerospace Applications. Materials Science and Engineering. A, 280, 102-107. https://doi.org/10.1016/S0921-5093(99)00674-7

[3] He, Y.D., Zhang, X.M. and You, J.H. (2007) Effect of Sc and Zr on Microstructure and Properties of Al-Zn-Mg-Cu alloy. Rare Metal Materials and Engineering, 36, 665-670.

[4] Xia, Z.F., Wang, L.L. and Lin, Z.M. (2012) Kinetics of Al-Zn-Mg-Cu Alloy during Aging Analysis. Shanghai Metal, 34, 1-3.

[5] Song, R.G. (2000) Research Status and Development Trend of High Strength Aluminum Alloy. Material Guide, 14, 20.

[6] Song, R.G. and Zhang, Q.Z. (2001) Heat Treatment Optimization for 7175 Aluminum Alloy by an Artificial Neural Network and a Genetic Algorithm. Journal of Materials Processing Technology, 117, 84-88. https://doi.org/10.1016/S0924-0136(01)01114-1

[7] Song, R.G. and Zhang, Q.Z. (2001) Heat Treatment Optimization for 7175 Aluminum Alloy by Genetic Algorithm. Materials Science and Engineering. C, 17, 133-137. https://doi.org/10.1016/S0928-4931(01)00321-6

[8] Robinson, J.S. and Tanner, D.A. (2006) The Influence of Aluminium Alloy Quench Sensitivity on the Magnitude of Heat Treatment Induced Residual Stress. Materials Science Forum, 524-525, 305-310. https://doi.org/10.4028/www.scientific.net/MSF.524-525.305

[9] Wloka, J., Hack, T. and Virtanen, S. (2007) Influence of Temper and Surface Condition on the Exfoliation Behaviour of High Strength Al-Zn-Mg-Cu Alloys. Corrosion Science, 49, 1437-1449. https://doi.org/10.1016/j.corsci.2006.06.033

[10] Liu, X.T. and Cui, J.Z. (2005) Progress in Research on Ultra High Strength Al-Zn-Mg-Cu Alloy. Materials Review, 19, 47-51.

[11] Tanner, D.A. and Robinson, J.S. (2006) Residual Stress Magnitudes and Related Properties in Quenched Aluminium Alloys. Materials Science and Technology, 22, 77-85. https://doi.org/10.1179/174328406X79414

[12] Imamura, T.J. (1999) Current Status and Trend of Applicable Material Technology for Aerospace Structure. Journal of Japan Institute of Light Metals, 49, 302. 
https://doi.org/10.2464/jilm.49.302

[13] Sun, H.J. and Yang, X.L. (2007) Development of Super High Strength Aluminum Alloy. Mechanical Engineer, 9, 41-42.

[14] Degischer, H.P., Lacom, W., Zahra, A. and Zahra, C.Y. (1980) Decomposition Processes in an $\mathrm{Al}-5 \% \mathrm{Zn}-1 \% \mathrm{Mg}$ Alloy. II.-Electronmicroscopic Investigations. Zeitschrift für Metallkunde, 71, 231-238.

[15] Han, X.-L., Xiong, B.-Q., Zhang, Y.-A., et al. (2010) Effect of Solution Treatment on Microstructures and Mechanical Properties of 7150 Aluminum Alloy. The Chinese Journal of Nonferrous Metals, 20, 1095-1101.

[16] Lin, Z.-Q., Zhu, J.-L., Sun, G.-J., et al. (1984) Effects of Cu on Precipitation Process and Microstructure Parameters of a-lzn-mg Alloy. Journal of Metals, 20, A54-A61.

[17] Duan, Y.-B., Tang, J., Huang, P., et al. (2003) Fracture Toughness of 7B04 Alloy. Journal of China Nonferrous Metals, 13, 216-221.

[18] Chen, K.H., Liu, H.W., Zhang, Z., et al. (2003) The Improvement of Constituent Dissolution and Mechanical Properties of 7055 Aluminum Alloy by Stepped Heat Treatments. Journal of Materials Processing Technology, 142, 190-196. https://doi.org/10.1016/S0924-0136(03)00597-1

[19] Qin, F.X., Zhang, B.J. and Zeng, M.G. (2001) Study on Age Hardening Characteristics and Stress Corrosion Properties of 7055 Super Aluminum Alloy. Light Alloy Processing Technology, No. 10, 36-39.

[20] Li, C.G., Wu, S.J. and Sheng, D.L. (2002) Advanced Aluminum Alloy in Aviation Industry Application and Development. Transactions of Nonferrous Metals Society of China, 12, 14-21. 